\title{
Carbonized lignosulfonate-based porous nanocomposites for adsorption of environmental contaminants
}

\author{
Jenevieve Yao, Karin Odelius and Minna Hakkarainen * (D)
}

\begin{abstract}
Carbon-based adsorbents possess exceptional adsorption capability, making them an ideal platform for the remediation of environmental contaminants. Here, we demonstrate carbonized lignosulfonate (LS)-based porous nanocomposites with excellent adsorption performance towards heavy metal ions and cationic dye pollutants. Through microwave-assisted hydrothermal carbonization, a green approach was employed to carbonize lignosulfonate to carbon spheres. The LS-derived carbon spheres were then oxidized into nanographene oxide $(\mathrm{nGO})$ carbon dots. A facile two-step procedure that involved the self-assembly of $\mathrm{nGO}$ and gelatin into a hydrogel precursor coupled with freeze-drying enabled the construction of three-dimensional (3D) free-standing porous composites without the use of organic solvents or chemical crosslinking agents. The favorable pore structure and abundance of surface functional groups on the $\mathrm{nGO} /$ gelatin porous composite proved to substantially facilitate the adsorption of $\mathrm{Cu}(\mathrm{II})$ in comparison to conventionally-used activated carbon. Further enhancement of adsorption performance was achieved by introducing additional surface functional groups through a non-covalent functionalization of the porous composite with lignosulfonate. The presence of negatively-charged sulfonate groups increased the $\mathrm{Cu}(\mathrm{II})$ equilibrium adsorption capacity $(66 \mathrm{mg} / \mathrm{g})$ by $24 \%$ in comparison to the non-functionalized nGO/gelatin counterpart. Both functionalized and non-functionalized composites exhibited significantly faster adsorption rates (40 min) compared to many graphene- or GO-based adsorbents reported in literature. In addition to the adsorption of heavy metal ions, the composites also demonstrated good adsorption capacity towards cationic dyes such as methylene blue. This paves the way for a high value-added application of lignin in environmental remediation and opens up new possibilities for the development of sustainable materials for adsorption and water purification.
\end{abstract}

Keywords: Graphene oxide, Lignosulfonate, Hydrothermal carbonization, Water purification

\section{Introduction}

Graphene oxide (GO)-based materials are highly effective adsorbents for environmental remediation, but their widespread use is hindered by the high cost involved in GO synthesis. Graphite, the primary source of graphene, is derived from non-renewable reserves, and even more so the production of graphene and $\mathrm{GO}$ via synthetic routes from commercial precursors requires high

\footnotetext{
* Correspondence: minna@kth.se

Department of Fibre and Polymer Technology, KTH Royal Institute of Technology, Teknikringen 58, 10044 Stockholm, Sweden
}

temperatures and harsh reaction conditions $[1,2]$. In recent years, the use of biomass waste as a precursor to carbonaceous materials has emerged as an effective strategy towards both valorization of low-value resources, as well as an economical and sustainable pathway towards the preparation of valuable carbon-based functional materials [3-6]. Wood, the largest biomass resource on earth, is mainly composed of cellulose, hemicellulose, and lignin [7]. In the pulping industry, the extraction of cellulose from wood generates large amounts of lignin-rich residues [8]. In spite of the

\section{Springer Open}

(๑) The Author(s). 2020 Open Access This article is licensed under a Creative Commons Attribution 4.0 International License, which permits use, sharing, adaptation, distribution and reproduction in any medium or format, as long as you give appropriate credit to the original author(s) and the source, provide a link to the Creative Commons licence, and indicate if changes were made. The images or other third party material in this article are included in the article's Creative Commons licence, unless indicated otherwise in a credit line to the material. If material is not included in the article's Creative Commons licence and your intended use is not permitted by statutory regulation or exceeds the permitted use, you will need to obtain permission directly from the copyright holder. To view a copy of this licence, visit http://creativecommons.org/licenses/by/4.0/. 
copious amounts available as a side stream, lignin has so far only few low-value applications and it is mostly burned for energy production [8-10].

Lignin is a complex heterogeneous polymer composed in large part of $p$-coumaryl, coniferyl, and sinapyl alcohol building blocks making up a molecular chain with a large number of phenyl rings [10]. Due to the high carbon content of over $60 \%$, lignin is considered to be a very promising raw material for carbonaceous products [11-14]. In comparison to cellulose-rich biomass, lignin-rich biomass yield chars with higher thermal stability and lower reactivity as a result of their higher fixed carbon contents [5]. Several successful methods have been employed in the synthesis of carbonaceous materials from lignin-based precursors, including high temperature pyrolysis $[5,15]$ and hydrothermal carbonization (HTC) [10, 11]. In this work, we employ a green approach via microwave-assisted HTC as adapted from previous work on carbonization of various biopolymers [16-19]. In comparison to pyrolytic carbonization, HTC proceeds at much lower temperatures in a closed system, thus significantly reducing energy consumption and air pollution [11, 20]. Implemented in combination with microwave irradiation, which facilitates rapid volumetric heating, increased reaction rates, and shortened reaction times compared to conventional heating, a time-efficient, cost-effective, and ecofriendly method of lignin carbonization is enabled [21, 22].

Herein, we investigate the feasibility of utilizing carbonized lignosulfonate-based $\mathrm{nGO}$ as a building block for the development of porous $\mathrm{nGO}$ /gelatin nanocomposites as adsorbents for wastewater purification. First, we employ a two-step reaction that involves carbonization of lignosulfonate and oxidation of the resulting carbon product to derive nGO. Next, we construct three-dimensional freestanding porous composites through the self-assembly of nGO and gelatin into hydrogel precursors in the absence of any chemical crosslinking agent. To further enhance the adsorption performance of the composites, additional active sites for adsorption in the form of negatively-charged sulfonate groups are introduced via non-covalent functionalization with lignosulfonate. Hence, we explore the adsorption performance of sustainable and environment friendly lignosulfonate-based nanocomposites towards the remediation of heavy metal ions and cationic dye pollutants from wastewater.

\section{Experimental}

\section{Reagents and materials}

Sodium lignosulfonate $(\mathrm{LS})\left(\mathrm{M}_{\mathrm{w}}=20,300\right.$; $\mathrm{PDI}=2.34 ; 5-$ $7 \%$ methoxy content, $<6 \%$ water) was obtained from Tokyo Chemical Industry UK Ltd. Gelatin, sulfuric acid $\left(\mathrm{H}_{2} \mathrm{SO}_{4} ; 95-98 \%\right)$, nitric acid $\left(\mathrm{HNO}_{3} ; 70 \%\right)$, copper sulfate pentahydrate $\left(\mathrm{CuSO}_{4} \cdot 5 \mathrm{H}_{2} \mathrm{O}\right)$, poly(ethyleneimine)
(PEI) $\left(\mathrm{M}_{\mathrm{w}}=750,000,50 \% \mathrm{w} / \mathrm{v}\right.$ in $\left.\mathrm{H}_{2} \mathrm{O}\right)$, and methylene blue $\left(\mathrm{C}_{16} \mathrm{H}_{18} \mathrm{ClN}_{3} \mathrm{~S} ; \geq 82 \%\right)$ were obtained from SigmaAldrich. All chemicals were used as received. Commercially available activated carbon for aquarium filtration systems was obtained from Fluval Carbon, Hagen Inc.

\section{Synthesis of nanographene oxide ( $\mathrm{nGO}$ ) from LS}

nGO was synthesized by oxidation of lignosulfonatederived carbon spheres (CS), that were obtained through an acid-catalyzed microwave-assisted carbonization process adapted from previous work $[18,19]$. Here, LS was used instead of $\alpha$-cellulose or starch as biopolymer, and the carbonization temperature was increased from $220^{\circ} \mathrm{C}$ to $240^{\circ} \mathrm{C}$. Briefly, CS were produced through the carbonization of $2 \mathrm{~g}$ of $\mathrm{LS}$ in $20 \mathrm{~mL}$ of aqueous $\mathrm{H}_{2} \mathrm{SO}_{4}$ solution $(0.01 \mathrm{~g} / \mathrm{mL})$ for $2 \mathrm{~h}$ with a ramp time of $20 \mathrm{~min}$ using a flexiWAVE microwave device (Milestone Inc.). The obtained CS were sonicated in a $70 \% \mathrm{HNO}_{3}$ aqueous solution $(1: 100 \mathrm{w} / \mathrm{w})$ for $30 \mathrm{~min}$. Oxidation was performed at $90{ }^{\circ} \mathrm{C}$ with constant stirring for $30 \mathrm{~min}$. Cold deionized water was poured into the solution to stop the reaction. The solvent was removed via rotary evaporation, after which the produced nGO was freeze-dried and stored in vacuum at room temperature for at least $48 \mathrm{~h}$ before use.

\section{Preparation of LS-functionalized porous $\mathrm{nGO} /$ gelatin nanocomposites}

Porous nGO-gelatin composites were first prepared via self-assembly forming hydrogels, followed by freezedrying. First, aqueous suspensions of nGO $(10 \mathrm{mg} / \mathrm{mL})$ were prepared by stirring $100 \mathrm{mg}$ of the LS-derived nGO in $10 \mathrm{~mL}$ of deionized $\mathrm{H}_{2} \mathrm{O}$ for $1 \mathrm{~h}$, followed by sonication for $30 \mathrm{~min}$. Different predetermined amounts of LS were then dispersed in the $\mathrm{nGO}$ suspensions via sonication for $10 \mathrm{~min}$. Hydrogel self-assembly was initiated according to a previous procedure $[23,24]$, with the important difference that here, zero-dimensional nGO derived from LS was utilized instead of the (in lateral dimension) microsized GO from commercial graphite powder. Briefly, 1.5 $\mathrm{mL}$ of aqueous gelatin solution with varying concentrations was added drop-wise to the $\mathrm{nGO} /$ /ignosulfonate suspension, prompting immediate hydrogel formation. The mixture was subsequently heated to $60^{\circ} \mathrm{C}$ for $5 \mathrm{~min}$ to induce the formation of covalent and non-covalent bonds between nGO and gelatin, which acts as a reducing agent and can partially reduce nGO. The composition of the prepared nanocomposites are found in Table 1 and denoted as nGOX-GelY-LSZ where $X: Y: Z$ indicate the nGO: gelatin:lignosulfonate mass ratio. The prepared hydrogels were washed in deionized water for 1 week with regular water changes. Finally, the hydrogels were freeze-dried for $48 \mathrm{~h}$ to obtain porous composite materials. All 
Table 1 Compositions by mass of the porous composites

\begin{tabular}{llll}
\hline & nGO (mg) & Gelatin (mg) & LS (mg) \\
\hline nGO1-Gel1 & 100 & 100 & 0 \\
nGO1-Gel1.5 & 100 & 150 & 0 \\
nGO1-Gel2 & 100 & 200 & 0 \\
nGO1-Gel1-LS0.1 & 100 & 100 & 10 \\
nGO1-Gel1.5-LS0.1 & 100 & 150 & 10 \\
nGO1-Gel2-LS0.1 & 100 & 200 & 10 \\
nGO1-Gel1-LS0.05 & 100 & 100 & 5 \\
nGO1-Gel1-LS0.2 & 100 & 100 & 20 \\
\hline
\end{tabular}

characterizations and adsorption tests were executed on granulated nGO/gelatin composites.

\section{Characterization of LS-derived carbon products and LS- functionalized nGO/gelatin composites}

Apparent porosity was determined using Eq. 1, where $M_{1}$ is the mass of the dry sample, $M_{2}$ is the mass of the saturated sample after immersion in deionized water, $\rho$ is the density of water, and V is the volume of the saturated sample.

$$
\operatorname{Porosity}(\%)=\frac{\left(M_{2}-M_{1}\right)}{\rho V} \times 100
$$

The analysis of functional groups was performed using Fourier transform infrared spectroscopy (FT-IR) and carried out by PerkinElmer Spectrum 2000 FTIR spectrometer equipped with attenuated total reflectance (ATR) accessory (Graseby Sperac). All spectra were recorded in the wavenumber range of $4000-600 \mathrm{~cm}^{-1}$ using 16 scans at a resolution of $4 \mathrm{~cm}^{-1}$.

Characterization of structural disorder in the lattice of the carbon products was performed via confocal Raman spectroscopy. Raman measurements were conducted on a HR800 UV Jobin Yvon Raman spectrometer (Horiba Scientific, Ltd.) with a solid-state laser set at an excitation wavelength of $514 \mathrm{~nm}$. The laser was focused on the sample by passing through a 50x objective lens, and the Raman signal was collected by the same lens using a 600 groove $\mathrm{mm}^{-1}$ density grating. Spectra were acquired at a resolution of $1 \mathrm{~cm}^{-1}$ at 7 accumulations with an acquisition time of $40 \mathrm{~s}$.

The thermal behavior and decomposition profiles of the carbon products and composites were investigated through thermogravimetric analysis (TGA), which was performed on a Mettler-Toledo TGA/SDTA 851e instrument. The samples (5-6 mg) were placed in $70 \mu \mathrm{L}$ alumina cups and heated in a temperature range of 25$800{ }^{\circ} \mathrm{C}$ at a rate of $10^{\circ} \mathrm{C} / \mathrm{min}$ in $\mathrm{N}_{2}$ atmosphere set to a flow rate of $50 \mathrm{~mL} / \mathrm{min}$.
Transmission electron microscopy (TEM) images of the CS and nGO were acquired on a Hitachi HT7700 instrument. For TEM sample preparation, CS and nGO were dispersed in ethanol $(0.2 \mathrm{mg} / \mathrm{mL})$ via sonication for 30 min and drop casted on an EM-TEC formvar carbon support film on a copper 200 square mesh (Micro to Nano V.O.F.).

In the case of the composites, high-resolution images were taken on an ultrahigh resolution field emission scanning electron microscope, FE-SEM Hitachi S-4800. For SEM sample preparation, the samples were attached on an aluminum stub using carbon tape, and sputter coated with a platinum/palladium $(\mathrm{Pt} / \mathrm{Pd})$ coater target at $2 \mathrm{~nm}$ thickness using a Cressington 208HR Sputter Coater (Cressington Scientific Instruments, Ltd.).

Elemental analysis of the carbon products and the composites before and after heavy metal- or dyeadsorption were performed via energy-dispersive $\mathrm{x}$-ray spectroscopy (EDX) measurements on Pt/Pd-coated samples using an X-Max ${ }^{N} 80$ Silicon Drift Detector $(\mathrm{Ox}-$ ford Instruments) attached to the Hitachi SEM S-4800. Quantitative EDX measurements were performed by point analysis of randomly selected sites on the specimen using an electron beam accelerating voltage of 15 $\mathrm{kV}$ for all samples with the exception of the analysis of the composites after $\mathrm{Cu}$-adsorption, for which $20 \mathrm{kV}$ was used. Elemental compositions are given as an average of 10 point analysis measurements for each sample.

\section{Batch adsorption test}

Batch adsorption experiments were carried out to investigate the adsorption behavior of the composites towards $\mathrm{Cu}(\mathrm{II})$ and methylene blue (MB), respectively. A stock solution of $\mathrm{Cu}(\mathrm{II})(0.008 \mathrm{M})$ was prepared by dissolving $1.96 \mathrm{~g}$ of the $\mathrm{CuSO}_{4} \cdot 5 \mathrm{H}_{2} \mathrm{O}$ in $1000 \mathrm{~mL}$ of deionized water. All subsequent solutions with varying $\mathrm{Cu}(\mathrm{II})$ concentrations were prepared by diluting the stock solution. The $\mathrm{pH}$ values of all solutions were adjusted to $\mathrm{pH} 5.2$ via drop-wise additions of $0.01 \mathrm{M} \mathrm{NaOH}$ or $\mathrm{HCl}$. For the adsorption of methylene blue, an aqueous solution $\left(9.38 \times 10^{-5} \mathrm{M}\right)$ was prepared. The $\mathrm{pH}$ of the MB solution was adjusted to $\mathrm{pH} 9$ to maximize dye adsorption $[25,26]$ with drop-wise additions of $0.01 \mathrm{M} \mathrm{NaOH}$. Ten milligram of the composite was added to $30 \mathrm{~mL}$ of $\mathrm{Cu}(\mathrm{II})$ solution or $20 \mathrm{~mL}$ of MB solution. The solution was then agitated at $240 \mathrm{rpm}$ using a rotary shaker at room temperature until equilibrium adsorption was reached. Dye adsorption was carried out under dark conditions to prevent photocatalytic degradation of methylene blue.

A UV-vis absorption spectrophotometer (Shimadzu UV-2550) was used to determine the concentrations of $\mathrm{Cu}(\mathrm{II})$ at $\lambda=625 \mathrm{~nm}$ after complexation with poly(ethyleneimine) (PEI), which enabled detection of low concentrations of the ion (Supporting Information 1), or 
MB at $\lambda_{\max }=663 \mathrm{~nm}$. Calibration curves were constructed to correlate the concentration of $\mathrm{Cu}(\mathrm{II})\left(\mathrm{R}^{2}=\right.$ 0.9965 , Fig. S2) or $M B\left(R^{2}=0.9895\right.$, Fig. S3) with their respective maximum absorbances. All adsorption experiments were carried out in duplicate, and average values were used in data analysis. The adsorption capacity $\left(\mathrm{q}_{\mathrm{t}}\right)$ of the porous composite was calculated according to Eq. 2, where $C_{0}(\mathrm{mg} / \mathrm{L}), C_{t}(\mathrm{mg} / \mathrm{L})$, and $C_{e}(\mathrm{mg} / \mathrm{L})$ are the initial adsorbate concentration, the adsorbate concentration at time $t$, and the adsorbate concentration at the equilibrium time, respectively. V (L) stands for the volume of the adsorption solution used, and $\mathrm{m}$ (g) represents the dry weight of the sample.

$$
q_{t}=\frac{\left(C_{0}-C_{t}\right) V}{m}
$$

\section{Recyclability test}

The reusability of the composite adsorbent was investigated through five cycles of $\mathrm{Cu}(\mathrm{II})$ adsorption and desorption. For every adsorption cycle, the composite material was immersed in fresh solutions of $\mathrm{Cu}(\mathrm{II})$ $(0.006 \mathrm{M}, 30 \mathrm{~mL}, \mathrm{pH} 5.2)$ for $40 \mathrm{~min}$ with constant agitation at $240 \mathrm{rpm}$. After each adsorption test, the $\mathrm{Cu}(\mathrm{II})-$ loaded samples were washed with aqueous $\mathrm{HCl}$ solution $(0.1 \mathrm{M})$ for $2 \mathrm{~h}$ at $240 \mathrm{rpm}$. The regenerated samples were then washed in deionized water and freeze-dried for the subsequent adsorption cycle. The recyclability test was performed in duplicate.

\section{Results and discussion}

Porous nanographene oxide (nGO)/gelatin nanocomposites were developed by a self-assembly strategy utilizing lignosulfonate-derived carbon products as building blocks. First, sodium lignosulfonate (LS) was hydrothermally carbonized into carbon spheres (CS). The CS were then oxidized into nanographene oxide (nGO)-type carbon dots to introduce oxygen-containing functional groups that give rise to improved chemical reactivity and dispersibility in polar solvents [27, 28]. Oxygen functionalities also served as tethering sites onto which LS was noncovalently attached to further enhance adsorption properties. Self-assembly of a three-dimensional porous hydrogel was thereafter initiated by using gelatin as a low cost, highly available and biodegradable crosslinker. In a final step to obtain lightweight, free-standing materials in aqueous environments, the hydrogels were freeze-dried to fabricate porous $\mathrm{nGO} /$ gelatin nanocomposites. Adsorption tests were performed to evaluate the adsorption performance of the composites towards $\mathrm{Cu}(\mathrm{II})$ and methylene blue (MB).

\section{Characterization of lignosulfonate (LS)-derived carbon products}

FT-IR spectroscopy (Fig. 1a) indicates that during the hydrothermal carbonization of sodium lignosulfonate, dehydration occurs and ether linkages are broken, while carboxyl and/or carbonyl groups are formed on the resulting CS product. Pure LS is characterized by a broad $\mathrm{O}-\mathrm{H}$ band at $3600-3000 \mathrm{~cm}^{-1}$, a stretching vibration peak of the aromatic ring skeleton $\mathrm{C}=\mathrm{C}$ groups at $1606 \mathrm{~cm}^{-1}$, a stretching vibration peak of C-O-C ether bonds at $1144 \mathrm{~cm}^{-1}$, and an $\mathrm{S}=\mathrm{O}$ stretching peak at $1040 \mathrm{~cm}^{-1}$. After carbonization, CS depicted similar characteristic peaks with the exception of the disappearance of the $\mathrm{C}-\mathrm{O}-\mathrm{C}$ ether peak and the appearance of peaks attributed to the $\mathrm{C}=\mathrm{O}\left(1724 \mathrm{~cm}^{-1}\right)$ and $\mathrm{C}-\mathrm{O}$ $\left(1225 \mathrm{~cm}^{-1}\right)$ stretching vibrations, which suggest the elimination of ether bonds [20,29] and the formation carboxyl and/or carbonyl groups [14, 30]. Additionally, the decrease in the intensity of the $\mathrm{O}-\mathrm{H}$ band indicates that dehydration of LS occurs during carbonization. The oxidation of carbonized LS to nGO, on the other hand, depicted a significant increase in oxygen-containing functional groups, that is the alcohol $(\mathrm{O}-\mathrm{H})$, carboxyl $(\mathrm{C}=\mathrm{O}$ and $\mathrm{C}-\mathrm{O})$, and epoxide $(\mathrm{C}-\mathrm{O}-\mathrm{C})$ groups as indicated by asymmetric ring deformation occurring at 920 $\mathrm{cm}^{-1}$. This is similar to what was observed for nGO synthesized through the same oxidation process from other biopolymer-derived CS [16, 19]. Finally, both CS and nGO maintained some of the sulfonate groups present in lignosulfonate, which thus persisted both carbonization and the acid treatment during the oxidation process.

An increase in the lattice defects of nGO compared to CS due to oxidation was confirmed via confocal Raman spectroscopy (Fig. 1b). D and G bands positioned at $1350-1400 \mathrm{~cm}^{-1}$ and $1590 \mathrm{~cm}^{-1}$, respectively, were observed for both carbon products CS and nGO, which is in agreement with what is typically observed for carbonaceous materials [31]. The D band corresponds to the presence of structural lattice defects, which arises from the cleavage of $\mathrm{sp}^{2}$ carbon bonds into $\mathrm{sp}^{3}$ bonds, while the $\mathrm{G}$ band represents graphitic domains $[32,33]$. The amount of lattice defects thus correlates with the $\mathrm{I}_{\mathrm{D}} / \mathrm{I}_{\mathrm{G}}$ ratio, which increases from 0.50 for CS to 0.71 for $\mathrm{nGO}$ (Supporting Information 2). This increase in $\mathrm{I}_{\mathrm{D}} / \mathrm{I}_{\mathrm{G}}$ ratio suggests the introduction of defects in the form of carboxyl, hydroxyl, and epoxide groups to the planar carbon structure of nGO. Similar results were shown in previous studies by our group that employed the same microwave-assisted HTC approach to carbonize different biomass or biopolymers into carbon sphere precursors, followed by the oxidation into nGO dots. For example, carbonized and oxidized $\alpha$-cellulose and carbonized and oxidized spent coffee grounds, which are of 

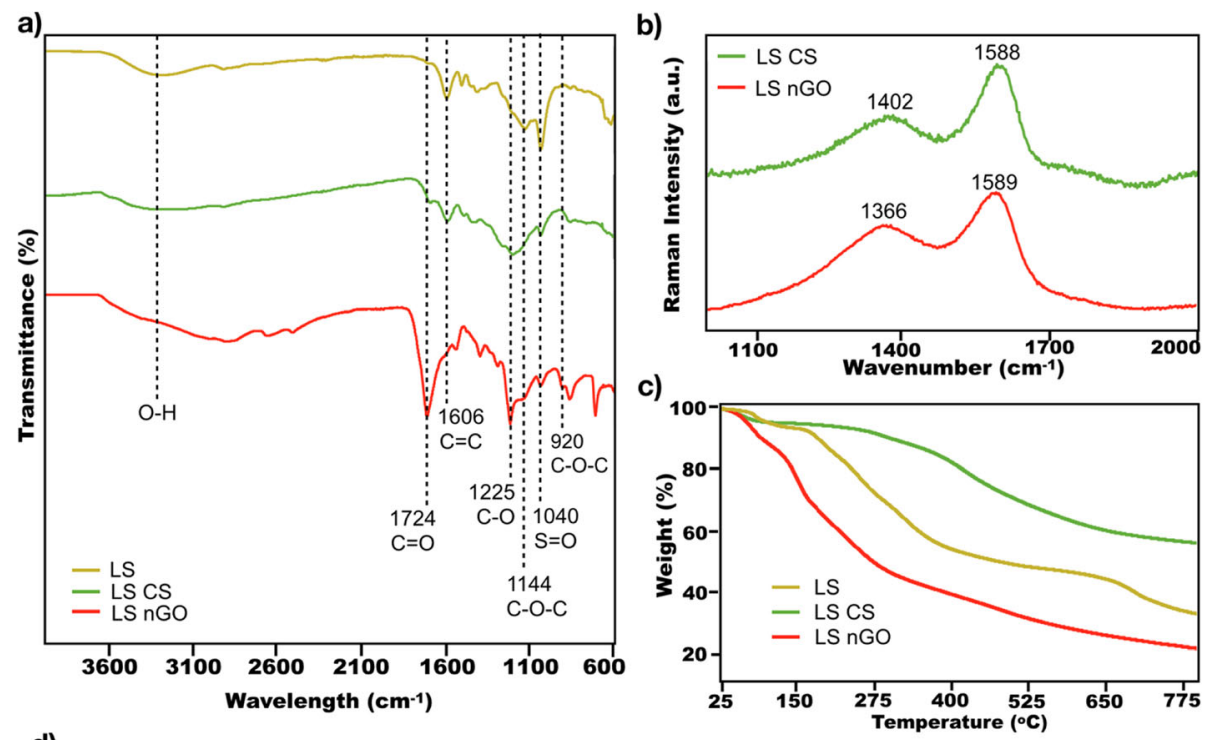

d)
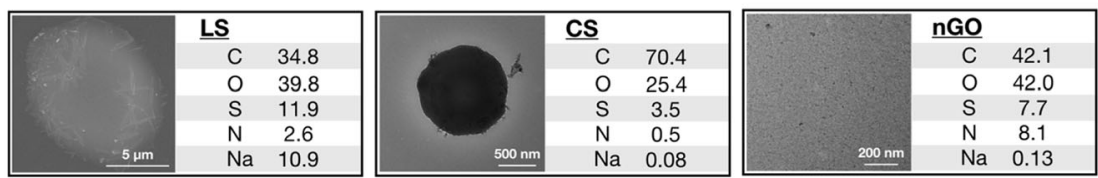

Fig. 1 a FT-IR spectra, b Raman spectra, c TGA curves, and d SEM and TEM images and elemental compositions of lignosulfonate (LS) and LSderived carbon products - carbon spheres (CS) and nanographene oxide ( $\mathrm{nGO}$ )

lignocellulosic nature and typically consits of $24 \%$ lignin [34], were revealed to possess X-ray powder diffraction (XRD) patterns featuring (002) facets of graphite and (001) lattice planes of graphene oxide, along with disordered carbons [19, 35]. The thickness of the graphene oxide sheets in both studies was approximately $1-3 \mathrm{~nm}$, indicating a few graphene oxide layers. Carbonized but not oxidized sodium lignosulfonate, on the other hand, was found to possess an XRD pattern distinct to graphite-like structures, but with larger interplanar distance due to the presence of some defects in the form of oxygen-containing groups and hybridized $\mathrm{sp}^{3}$ carbon [36].

The thermal decomposition behavior of the carbon products was investigated by TGA as shown in Fig. 1c. LS decomposed in three stages, as depicted by an initial mass loss between 60 and $70{ }^{\circ} \mathrm{C}$ due to water removal, a second mass loss at $150-400^{\circ} \mathrm{C}$, previously ascribed to the pyrolysis of oxygen-containing groups released as aromatics (e.g., phenol, guaiacol, or syringol), alkyls, $\mathrm{CO}_{2}$, $\mathrm{CO}$, and small molecules containing sulfur and sodium, and a final decomposition step at $630-760^{\circ} \mathrm{C}$ attributed to the loss of the remaining oxygen-containing groups on carbon edges [37]. LS-derived CS exhibits the same initial mass loss due to water removal, as well as a second decomposition stage occurring at a much higher temperature range $\left(230-600{ }^{\circ} \mathrm{C}\right)$. This decomposition step, with maximum mass loss occurring at $420^{\circ} \mathrm{C}$, was previously attributed to the cleavage of plasticizing side groups and formed functionalities from hydrothermal carbonization, which can result in a more cross-linked and thermally stable material [10]. The residue content of LS-derived CS was approximately $57 \mathrm{wt} \%$, which is much higher than both that of LS and nGO. This is proposed to be due to the large amount of stable phenolic structures that contribute to char formation through a condensation reaction [20]. In the case of nGO, rapid decomposition due to the pyrolysis of labile oxygencontaining functional groups is observed between 110 and $275^{\circ} \mathrm{C}$, with maximum mass loss occurring at $150^{\circ} \mathrm{C}$. Compared to CS, nGO clearly consists of a much larger amount of oxygen groups as manifested by its significantly lower residual weight, with a carbon content of $24 \%$.

The morphologies and elemental composition of the LS-derived carbon products were investigated using SEM-EDX and TEM (Fig. 1d). The original LS appeared invariably as spherical particles of a size up to several micrometers having needle-shaped filaments decorating its surface. During the HTC of LS, solid-solid conversion takes place as the preferred mechanism for carbon product formation, wherein only the dissolved lignin fragments and the surface fragments of non-dissolved lignin undergo carbonization [38]. It is reported that these decomposed hydrolyzed fragments are then converted to phenolic hydrochar, which finally settle on the surface of 
non-dissolved lignin to form the eventual structure of the carbon product [38]. The TEM micrographs of the carbonized product, CS, revealed that it has the same spherical structure and needle-like protrusions on its outer surface, but with a much smaller diameter of approximately one micrometer or less. The surface area of CS is expected to be very limited, as is typical of lignocellulosic biomass-derived hydrothermally carbonized products [39] and as demonstrated by a previous study on $\alpha$ cellulose similarly carbonized via microwave-assisted HTC [40]. Although the product of carbonization primarily consisted of the aforementioned spherically shaped particles, other carbon structures were also identified, such as nanotubes and nanodots (Fig. S7) similar to what has been uncovered before [36, 41]. Apart from elongated structures, plate-like structures such as carbon flakes have also been reported [36]. The non-ordered and heterogeneous structure of LS-derived CS could be explained by the heterogeneous nature of lignin and, specifically, by its lack of uniform repeating unit [10, 41, 42]. LS-derived nGO carbon dots formed by oxidation of CS, on the other hand, appeared to be more homogeneous and composed of $10-100 \mathrm{~nm}$ sized nGO dots. EDX analysis confirmed the successful introduction of oxygen-containing functional groups during the oxidation step. It also confirmed, in agreement with FTIR analysis, that some of the sulfonate groups of the LS starting material were preserved during carbonization and oxidation.

\section{Characterization of LS-derived $\mathrm{nGO/gelatin} \mathrm{porous}$ nanocomposites}

nGO/gelatin porous nanocomposites were fabricated through self-assembly of LS-derived nGO and gelatin into hydrogel precursors, which were subsequently freeze-dried. The apparent porosities of the adsorbents did not differ significantly among the different material compositions, and were within the range of $57-60 \%$ (Table S3). The structural stability of the porous materials, however, was highly dependent on the $\mathrm{nGO} /$ gelatin ratio. Hydrogel self-assembly did not occur in the absence of nGO or when the nGO content was lower than in nGO1-Gel2 or higher than in nGO1-Gel1. Similarly, gel formation also did not occur at low gelatin mass ratios (1:0.5 nGO:gelatin).

The main type of interaction between nGO and gelatin was elucidated via FT-IR spectroscopy (Fig. 2a). The evident reduction of oxygen-containing functional groups in the $\mathrm{nGO} /$ gelatin composites is exemplified by nGO1Gel1-LS0.1 suggesting covalent bond formation between nGO and gelatin. More specifically, a significant decrease in the peaks for carboxyl groups $(\mathrm{C}=\mathrm{O}$ at 1724 $\mathrm{cm}^{-1}$ and $\mathrm{C}-\mathrm{O}$ at $1225 \mathrm{~cm}^{-1}$ ) and epoxy groups (C-O-C

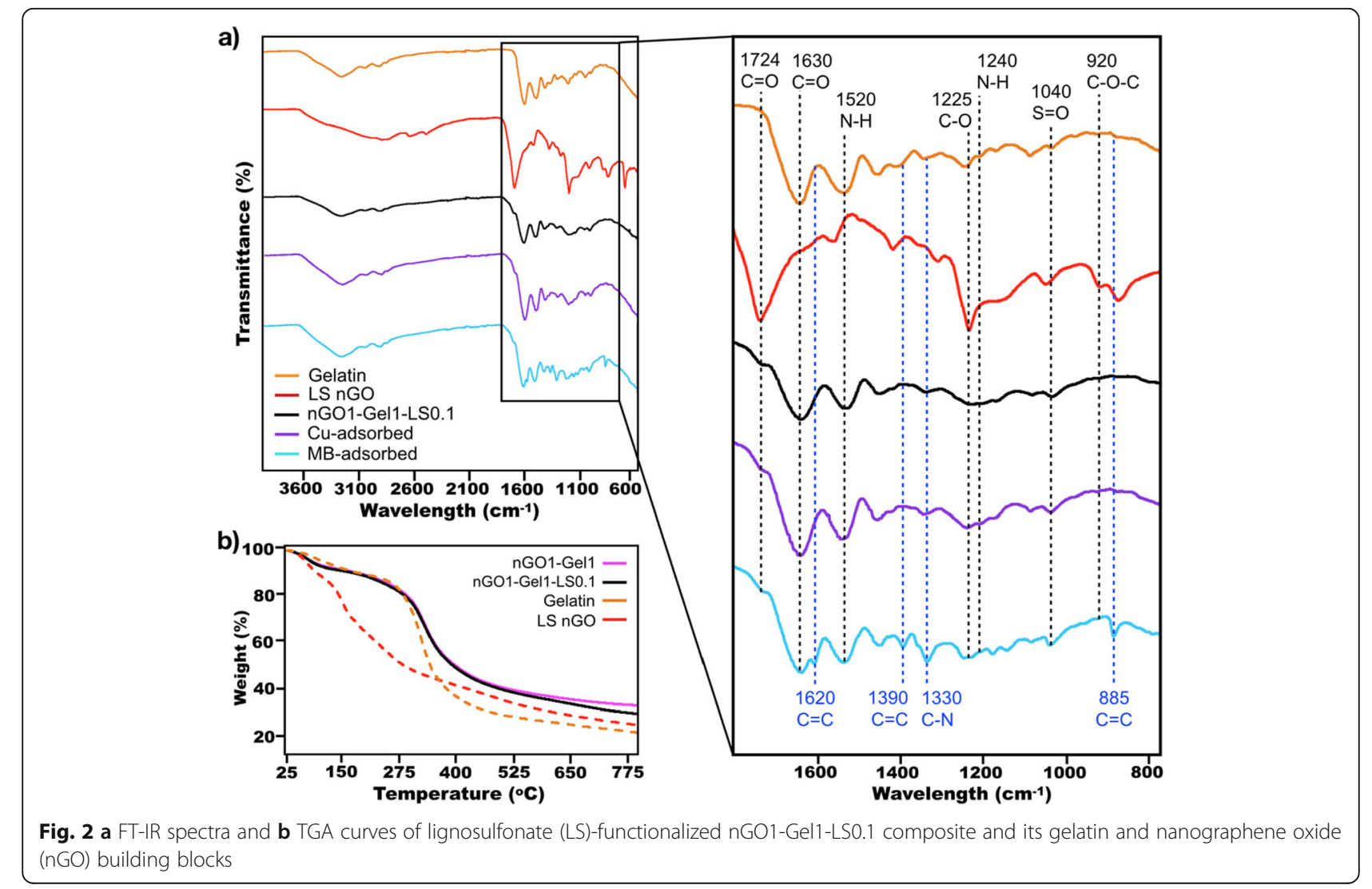


at $920 \mathrm{~cm}^{-1}$ ) indicates partial reduction of the oxygencontaining functional groups of nGO [24]. The weakening of peaks originating from carboxyl groups is most likely due to the amidation of the carboxyl groups of nGO by the amino groups of gelatin, and the disappearance of the epoxy peak is possibly caused by the ring-opening of the epoxy groups of nGO via nucleophilic substitution reaction with amino groups of gelatin [43-45].

TGA was performed to determine any changes in the thermal stability of the composites related to the composition of nGO, gelatin, and LS building blocks (Fig. 2b). The significant increase in decomposition temperature of the non-functionalized (nGO1-Gel1) and LS-functionalized (nGO1-Gel1-LS0.1) composites in comparison to that of LS nGO suggests enhancement of thermal stability, likely due to the strong interfacial interactions between nGO and the polar groups of gelatin $[24,46,47]$. Apart from the pyrolysis of oxygen-containing functional groups, the weight loss of approximately $50 \mathrm{wt} \%$ between 270 and $460^{\circ} \mathrm{C}$ could also be attributed to the pyrolysis of grafted gelatin, which has a decomposition temperature between 275 and $390^{\circ} \mathrm{C}$.

The non-functionalized (nGO1-Gel1) and LSfunctionalized (nGO1-Gel1-LS0.1) composites both featured open and interconnected porous networks (Fig. 3) with equal apparent porosities of $57 \%$. The LSfunctionalized composite, however, possessed more uniformly sized pores in comparison to its nonfunctionalized counterpart (Fig. S8a,b). This could be explained by the dispersant effect of lignosulfonate, which, due to its amphiphilic character and negatively-charged functional groups, could have facilitated the efficient dispersion of nGO within the porous composites via electrostatic repulsion [48]. Elemental maps of the materials obtained via EDX demonstrated the presence and even distribution of sulfur across the surfaces of both non-functionalized and LS-functionalized composites, whereas a higher amount of sulfonate groups were present in the latter. The notable increase in sulfur content from 1.1 to $4.6 \mathrm{wt} \%$ on the surface of the composites after functionalization with LS indicates successful addition of LS via noncovalent bonds.

\section{Adsorption of copper and methylene blue}

Compared to plain nGO/gelatin, the LS-functionalized nGO/gelatin composites demonstrated enhanced adsorption capacity towards $\mathrm{Cu}(\mathrm{II})$ due to the additional active sites from lignosulfonate. Figure $4 \mathrm{a}$ and $\mathrm{b}$ show the real-time monitoring $\mathrm{Cu}(\mathrm{II})$ adsorption curves and pseudo-second order sorption kinetics (Fig. S5) of all samples, as well as that of commercial activated carbon. The adsorption capacities at equilibrium time are presented in Table 2, while the maximum adsorption capacity, $69 \mathrm{mg} / \mathrm{g}$, was determined from the Langmuir model (Fig. S6) shown in Fig. 4c. All samples, except nGO1-Gel1-LS0.2, showed higher adsorption capacities than activated carbon. This could be due to the larger pore size and better interconnectivity of $\mathrm{nGO}$ /gelatin composites compared to activated carbon, which
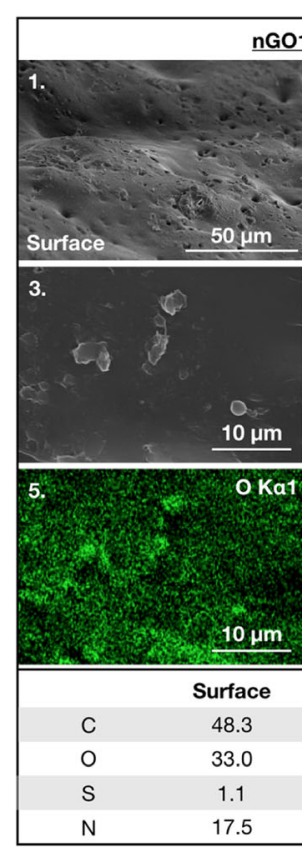
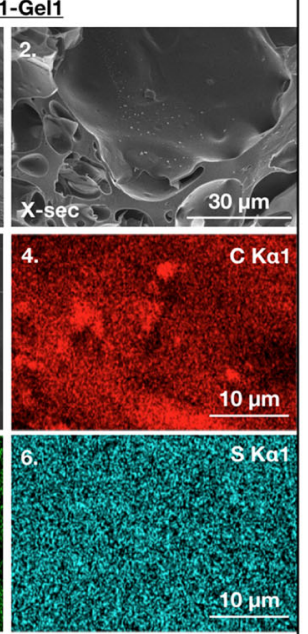

Cross-section

45.2

32.3

1.0

21.4

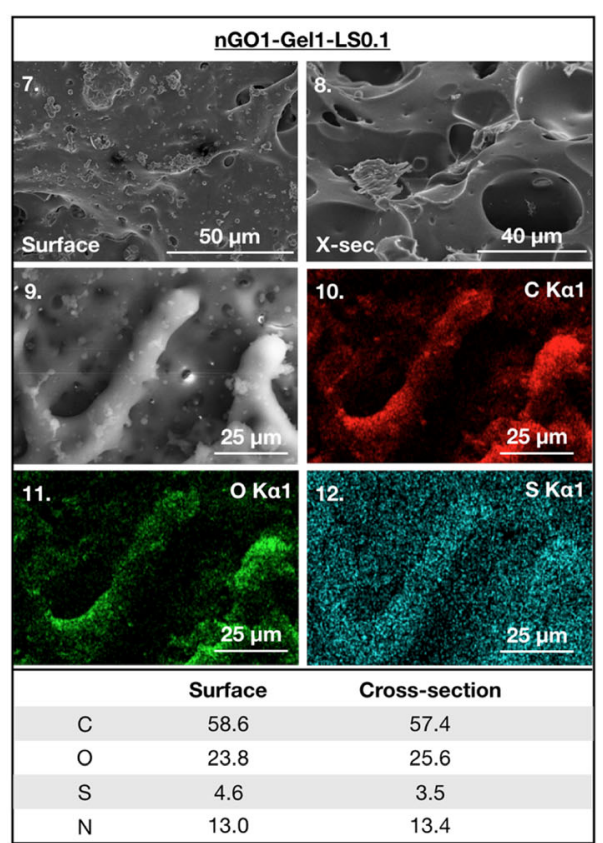

Fig. 3 SEM images and elemental maps (where carbon is represented in red, oxygen in green, and sulfur in blue) of non-functionalized nGO1Gel1 (1-6) and lignosulfonate (LS)-functionalized nGO1-Gel1-LS0.1 (7-12) composites and their surface and cross-sectional elemental compositions 

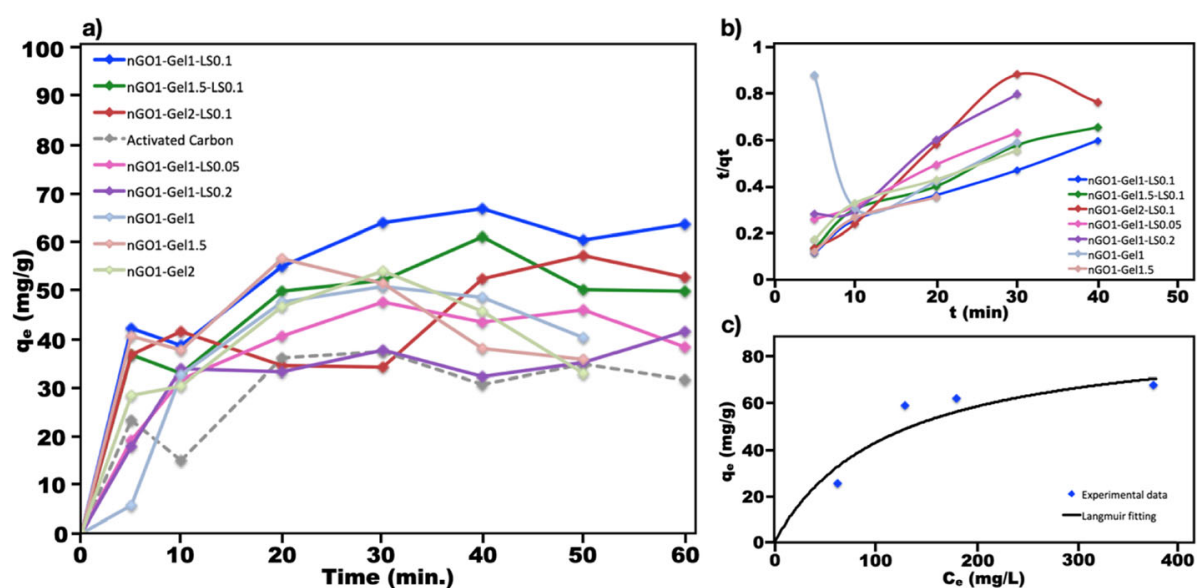

Fig. 4 a Real-time monitoring adsorption curves, b pseudo-second order adsorption kinetics, and $\mathbf{c}$ Langmuir adsorption isotherm (for nGO1Gel1-LS0.1) for Cu(II) adsorption

possessed a poorly connected network structure that possibly inhibited the efficient diffusion of pollutant ions or molecules (Fig. S9). The effect of pore structure on adsorption behavior was further demonstrated by the decreased adsorption capacity once the maximum gelatin and/or lignosulfonate content was reached. Apart from reduced porosity and inhomogeneous pore structure at high gelatin ratio (e.g. 1:2 nGO:gelatin), the reduction in adsorption capacity may also be due to the consumption of functional groups that act as active sites for adsorption, as a result of increased crosslink density between gelatin and nGO via covalent and noncovalent interactions [49]. As a result of this, nGO1-Gel2 and nGO1Gel2-LS0.1 both exhibited lower adsorption capacities compared to their lower gelatin content counterparts. Lignosulfonate, on the other hand, has the tendency to self-crosslink when present in excess amount [48], thereby resulting in blockage of pores, which can reduce the adsorption performance of the composites as observed for nGO1-Gel1-LS0.2, in comparison those functionalized with lower amount of lignosulfonate.
The LS-functionalized composites with LS:nGO mass ratio of 1:10 all exhibited enhanced adsorption capacities towards $\mathrm{Cu}$ (II) in comparison to their non-functionalized counterparts. This demonstrates that the increased number of negatively-charged oxygen-containing functional groups facilitates the adsorption of positively-charged $\mathrm{Cu}$ (II) ions via electrostatic attraction. Furthermore, along with carboxyl groups of nGO, sulfonate groups from LS have been shown to possess greater capability to capture pollutants than the epoxy and hydroxy groups because of their probable position on the $\mathrm{sp}^{3}$-hybridized edge of nGO, thereby acting as a "netting twine" that could extend to a longer range and increase the probability of interaction with ionic pollutants [50]. The maximum adsorption capacity of the LS-functionalized nGO1-Gel1-LS0.1 was $69 \mathrm{mg} / \mathrm{g}$, which is comparable with other carbonaceous adsorbents (Table 3). Furthermore, the time to reach equilibrium adsorption-desorption was only $40 \mathrm{~min}$, which is significantly faster than equilibrium times of many adsorbents $[51,53,55]$. It should be noted, however, that a direct comparison between the different adsorbents

Table 2 Equilibrium Cu(II) adsorption capacities of non-functionalized and lignosulfonate (LS)-functionalized composites

\begin{tabular}{lll}
\hline & Equilibrium Adsorption Capacity (mg/g) & Equilibrium Time (min.) \\
\hline nGO1-Gel1 & 50 & 30 \\
nGO1-Gel1.5 & 56 & 20 \\
nGO1-Gel2 & 54 & 30 \\
nGO1-Gel1-LS0.1 & 66 & 40 \\
nGO1-Gel1.5-LS0.1 & 61 & 40 \\
nGO1-Gel2-LS0.1 & 57 & 50 \\
nGO1-Gel1-LS0.05 & 47 & 30 \\
nGO1-Gel1-LS0.2 & 37 & 30 \\
Activated Carbon & 37 & 30 \\
\hline
\end{tabular}


Table 3 Comparison of Cu(II) adsorption capacities of various carbonaceous adsorbents

\begin{tabular}{|c|c|c|c|c|c|c|}
\hline Adsorbent & $\begin{array}{l}\text { Max. Adsorption Capacity } \\
(\mathrm{mg} / \mathrm{g})\end{array}$ & $\begin{array}{l}\text { Equilibrium } \\
\text { Time }\end{array}$ & $\begin{array}{l}\text { Adsorbent Dosage } \\
(\mathrm{mg})\end{array}$ & $\begin{array}{l}\text { Initial Cu(II) Conc. } \\
\text { (M) }\end{array}$ & $\begin{array}{l}\mathrm{Cu}(\mathrm{II}) \text { Volume } \\
(\mathrm{mL})\end{array}$ & Ref. \\
\hline Oxidized activated carbon & 23 & $3 \mathrm{~h}$ & 800 & $3.9 \times 10^{-4}$ & 800 & {$[51]$} \\
\hline Graphene aerogel & 19 & $15 \mathrm{~min}$. & 60 & $1.3 \times 10^{-3}$ & 100 & {$[52]$} \\
\hline Sodium alginate/GO aerogel & 98 & $3 \mathrm{~h}$ & - & $7.9 \times 10^{-3}$ & - & {$[53]$} \\
\hline Calcium alginate/GO aerogel & 98 & $40 \mathrm{~min}$. & 50 & $1.5 \times 10^{-3}$ & 50 & [54] \\
\hline GO/chitosan hydrogel & 63 & $10 \mathrm{~h}$ & 12.5 & $1.5 \times 10^{-3}$ & 100 & {$[55]$} \\
\hline $\begin{array}{l}\text { Graphene/acid-treated MWCNT } \\
\text { aerogel }\end{array}$ & 33 & - & 10 & $7.5 \times 10^{-4}$ & 50 & {$[56]$} \\
\hline $\begin{array}{l}\text { LS-functionalized nGO/gelatin } \\
\text { aerogel }\end{array}$ & 69 & $40 \mathrm{~min}$. & 10 & $6 \times 10^{-3}$ & 30 & $\begin{array}{l}\text { This } \\
\text { work }\end{array}$ \\
\hline
\end{tabular}

is difficult because adsorption behavior is affected by several factors, such as adsorbent dosage, initial adsorbate concentration, and volume of adsorbate solution, to name a few.

Electrostatic interactions were assumed to be the mechanism that governed the adsorption of positively charged $\mathrm{Cu}(\mathrm{II})$ ions by $\mathrm{nGO}$ and LS with negativelycharged oxygen-containing functional groups and sulfonate groups. The potential of the composites for cationic dye adsorption was, therefore, also investigated. Methylene blue (MB) was chosen as the model cationic dye for adsorption on LS-functionalized nGO1-Gel1LS0.1 composite. The material exhibited an adsorption capacity of $38 \mathrm{mg} / \mathrm{g}$ after $130 \mathrm{~min}$. Compared to the adsorption of $\mathrm{Cu}(\mathrm{II})$, the adsorption of methylene blue occurred at a much slower pace; after $130 \mathrm{~min}$, a removal efficiency of $35 \%$ was achieved. It should be noted that adsorption equilibrium had not been reached yet. Apart from electrostatic forces, the adsorption of $\mathrm{MB}$ by graphene-based carbon materials has been reported to also be governed by $\pi-\pi$ stacking interactions and hydrogen bonding [57]. The differences in the adsorption performance towards $\mathrm{Cu}(\mathrm{II})$ and $\mathrm{MB}$ may be due to the large size of the dye compared to the heavy metal ion [58].

FT-IR spectroscopy was performed in order to elucidate the chemical alterations after adsorption of $\mathrm{Cu}(\mathrm{II})$ and MB on the nGO1-Gel1-LS0.1 composite (Fig. 2a). Several additional bands appeared after MB-adsorption, specifically at $885 \mathrm{~cm}^{-1}$ and within the range 1390$1450 \mathrm{~cm}^{-1}$. These bands are associated with the aromatic group $\mathrm{C}=\mathrm{C}$ bend and $\mathrm{C}=\mathrm{C}$ stretch, respectively. In addition, an increase in the intensity of the peak at 1331 $\mathrm{cm}^{-1}$ was observed, which indicated the presence of additional aromatic amine $\mathrm{C}-\mathrm{N}$ groups besides those provided by gelatin. These results confirmed the adsorption of MB. As expected, the spectrum of the composite after $\mathrm{Cu}$-adsorption exhibited no new peaks compared to pristine sample.
Morphological alterations and elemental compositions of nGO1-Gel1-LS0.1 after $\mathrm{Cu}(\mathrm{II})$ and MB-adsorption were investigated using SEM and EDX. Figure 5 shows the SEM images of the sample before and after the adsorption of $\mathrm{Cu}(\mathrm{II})$ and $\mathrm{MB}$. The adsorbed $\mathrm{Cu}(\mathrm{II})$ is revealed as crystal-like structures, which suggests that besides the adsorption of the heavy metal ion, the sulfate anion of the salt was also simultaneously adsorbed and formed a chelate complex [59]. After MB adsorption, spherical methylene blue particulates were found on the surface. To confirm the compositions of the surfaces and observed structures, elemental mapping and multipoint analysis via EDX were performed. Elemental maps after $\mathrm{Cu}$ (II) adsorption confirmed that the aforementioned crystal structures are mainly composed of copper. Up to $25 \mathrm{wt} \%$ of elemental copper was detected on the surface, while only $13 \mathrm{wt} \%$ was found in the crosssection. Similarly, a higher amount of sulfur, which indicated $\mathrm{MB}$ adsorption, was present on the surface after $\mathrm{MB}$ adsorption compared to the cross-section. This suggests the preferential adsorption of both $\mathrm{Cu}(\mathrm{II})$ and $\mathrm{MB}$ onto the surface of the composite, possibly due to the larger number of active sites from functionalized LS or to the limited diffusivity of the adsorbates through the pores.

\section{Recyclability test}

The reusability of the adsorbent is one of the key factors for potential use in industrial applications. Five cycles of adsorption-desorption were performed for the recyclability test (Fig. 6). After each $\mathrm{Cu}(\mathrm{II})$-adsorption cycle, the composite was regenerated via immersion in $0.1 \mathrm{M}$ aqueous $\mathrm{HCl}$ solution for $2 \mathrm{~h}$ prior to next readsorption. The sample was found to retain $79 \%$ of its adsorption capacity after the fifth cycle. This demonstrates that in spite of the use of a low concentration of acid and short regeneration time, the composite is adequately able to sustain its adsorption capacity. Additionally, $100 \%$ of the composite is reclaimed after the 

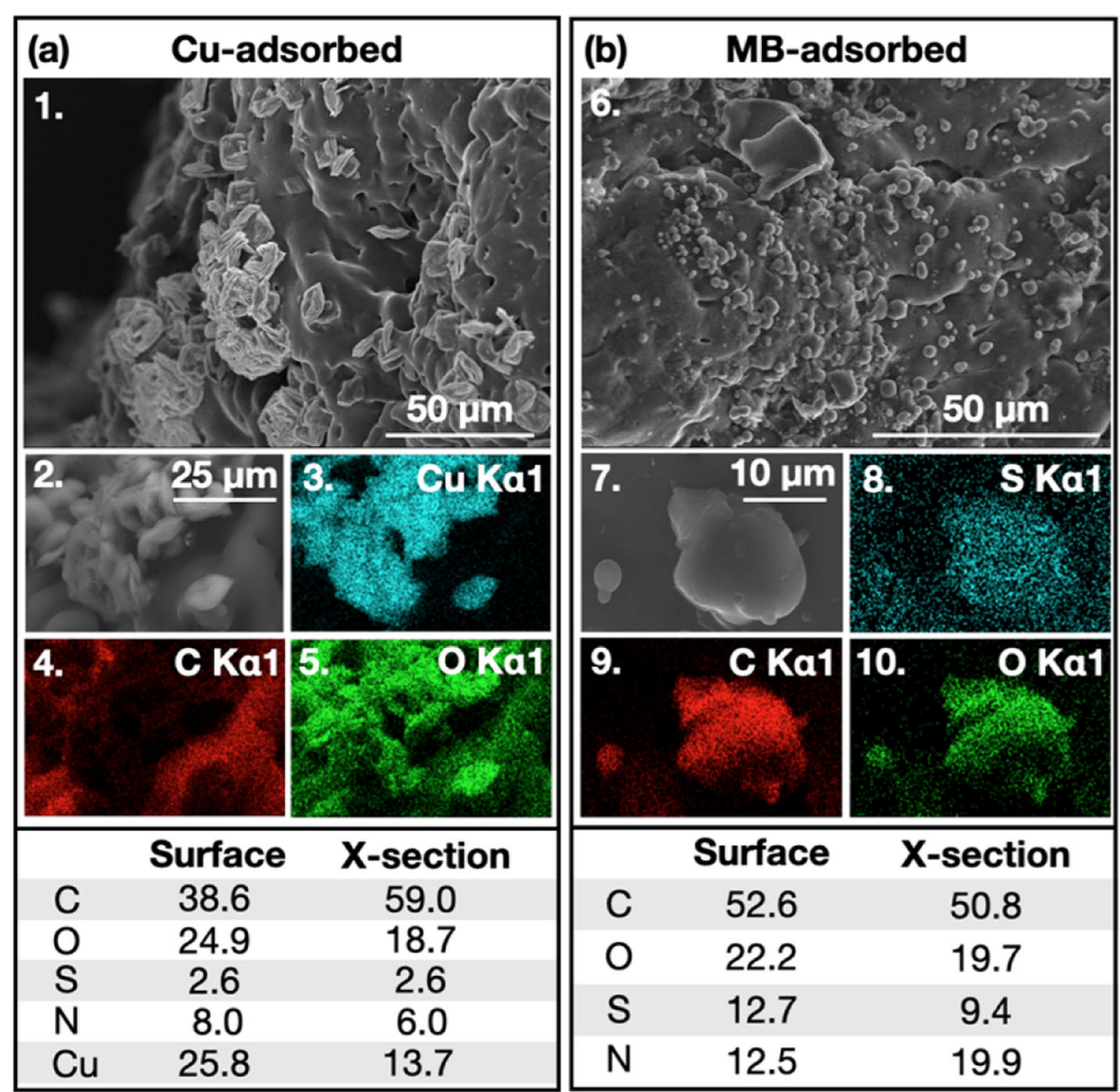

Fig. 5 SEM images and elemental maps of (a) Cu-adsorbed (1-5) and (b) methylene blue (MB)-adsorbed (6-10) nGO1-Gel1-LS0.1 composite and their surface and cross-sectional elemental compositions

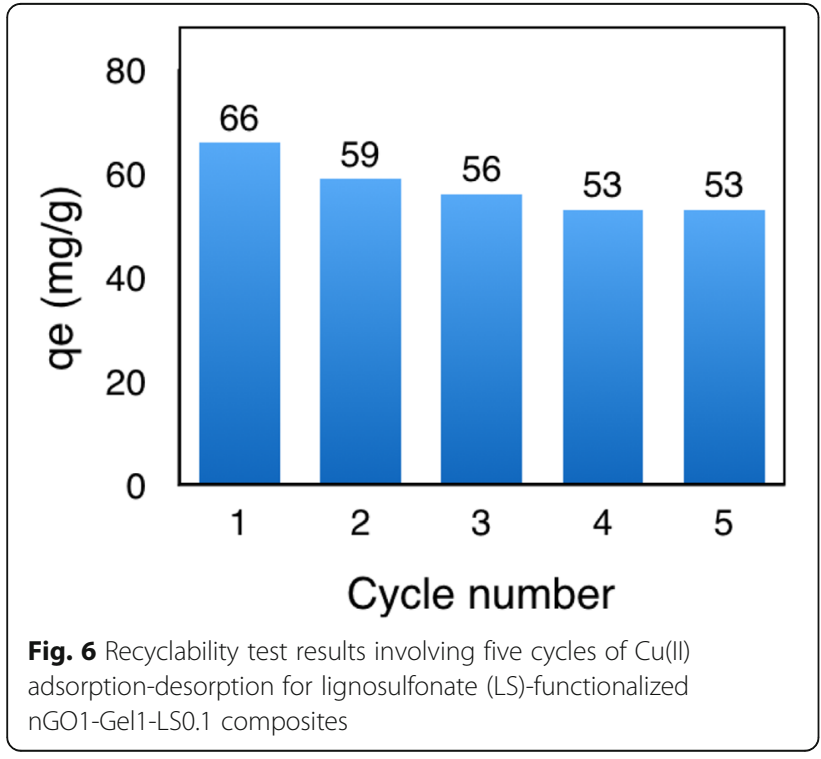

recyclability test. Other work reported in literature generally required a regeneration step with a stronger acid (e.g. $\mathrm{HNO}_{3}$ ) [60] at higher concentration (e.g. $0.3 \mathrm{M}$ $\mathrm{HCl})$ [61] and longer regeneration time (e.g. 24 h) [62]. It is possible that a longer regeneration time would further improve the reusability.

\section{Conclusions}

Free-standing three-dimensional (3D) lignin-derived porous nGO-based nanocomposites with excellent adsorption capacity for heavy metal ions and cationic dyes were successfully designed. nGO was derived through a two-step reaction, including carbonization and oxidation of lignosulfonate. The abundant oxygen functionalities on nGO conferred the construction of porous composites possessing three-dimensional (3D) interconnected network structure through the self-assembly of hydrogels using only gelatin as a crosslinker, coupled by freeze-drying method. Functionalization with lignosulfonate (LS) provided additional negatively-charged functional groups that served as active sites for adsorption and as dispersants for nGO via electrostatic repulsion. 
The dual role of LS enhanced the equilibrium adsorption capacity of the composites, which increased from $50 \mathrm{mg} /$ $\mathrm{g}$ to $66 \mathrm{mg} / \mathrm{g}$ for the non-functionalized and LSfunctionalized nGO1-Gel1-LS0.1 composites, respectively. Furthermore, the LS-functionalized composites demonstrated good reusability through a mild regeneration step, with $79 \%$ retention of the adsorption capacity after five adsorption-desorption cycles. Apart from heavy metal ions, the potential for cationic dye adsorption was also demonstrated as the LS-functionalized composite exhibited an adsorption capacity of $38 \mathrm{mg} / \mathrm{g}$ for methylene blue. The 3D porous constructs fabricated from lignosulfonate-derived functional carbon products were demonstrated as promising fully biobased materials for adsorption of environmental contaminants.

\section{Supplementary information}

Supplementary information accompanies this paper at https://doi.org/10. 1186/s42252-020-00008-8.

Additional file 1.

\section{Abbreviations}

ATR: Attenuated total reflectance; CS: Carbon spheres; EDX: Energy-dispersive $\mathrm{x}$-ray spectroscopy; FE-SEM: Field emission scanning electron microscopy; FTIR: Fourier transform infrared spectroscopy; GO: Graphene oxide; HTC: Hydrothermal carbonization; LS: Lignosulfonate; MB: Methylene blue; MWCNT: Multi-walled carbon nanotubes; nGO: Nanographene oxide; PDI: Polydispersity index; PEl: Polyethylene imine; TEM: Transmission electron microscopy; TGA: Thermogravimetric analysis; XRD: X-ray diffraction

\section{Acknowledgements}

Not applicable.

\section{Authors' contributions}

The manuscript was written through contributions of all authors. All authors have given approval to the final version of the manuscript.

\section{Funding}

The Swedish Research Council, VR, (Contract Grant 2018-03451) is gratefully acknowledged for financial support. Open access funding provided by Royal Institute of Technology

\section{Availability of data and materials}

Most of the data generated or analyzed during this study are included in this published article and its supplementary information files. Remaining data is available from the corresponding author on reasonable request.

\section{Competing interests}

The authors declare no competing financial interest.

Received: 23 February 2020 Accepted: 4 May 2020

Published online: 02 June 2020

\section{References}

1. U. Alvarez, C. Granda, R. Santamaria, R. Menendez, New alternatives to graphite for producing graphene materials. Carbon. 93, 812-818 (2015). https://doi.org/10.1016/j.carbon.2015.05.105

2. S.H. Jung, Y. Myung, B.N. Kim, I.G. Kim, I.K. You, T.Y. Kim, Activated biomassderived graphene-based carbons for supercapacitors with high energy and power density. Sci. Rep. (2018). https://doi.org/10.1038/s41598-018-20096-8

3. Z. Gao, Y. Zhang, N. Song, X. Li, Biomass-derived renewable carbon materials for electrochemical energy storage. Mat Res Lett 5, 69-88 (2017). https://doi.org/10.1080/21663831.2016.1250834
4. Q. Ma, Y. Yu, M. Sindoro, A.G. Fane, R. Wang, H. Zhang, Carbon-based functional materials derived from waste for water remediation and energy storage. Adv. Mater. (2017). https://doi.org/10.1002/adma.201605361

5. C.R. Correa, M. Stollovsky, T. Hehr, Y. Rauscher, B. Rolli, A. Kruse, Influence of the carbonization process on activated carbon properties from lignin and lignin-rich biomasses. ACS Sustain Chem Eng 5(9), 8222-8233 (2017). https://doi.org/10.1021/acssuschemeng.7b01895

6. L. Guardia, L. Suarez, N. Querejeta, V. Vretenar, P. Kotrusz, V. Skakalova, T. Centeno, Biomass waste-carbon/reduced graphene oxide composite electrodes for enhanced supercapacitors. Electrochim. Acta 298, 910-917 (2019). https://doi.org/10.1016/j.electacta.2018.12.160

7. C. Xu, M. Stromme, Sustainable porous carbon materials derived from wood-based biopolymers for CO2 capture. Nanomaterials (2019). https://doi. org/10.3390/nano9010103

8. W. Lan, J.S. Luterbacher, A road to profitability from lignin via the production of bioactive molecules. ACS Cent Sci 5(10), 1642-1644 (2019). https://doi.org/10.1021/acscentsci.9b00954

9. S.P. Leitner, G. Gratzl, C. Paulik, H.K. Weber, Carbon materials from lignin and sodium lignosulfonate via Diisocyanate cross-linking and subsequent carbonization. C. 1(1), 43-57 (2015). https://doi.org/10.3390/c1010043

10. H. Wikberg, T. Ohra-aho, F. Pileidis, M.M. Titirici, Structural and morphological changes in Kraft lignin during hydrothermal carbonization. ACS Sustain. Chem. Eng. 3(11), 2737-2745 (2015). https://doi.org/10.1021/ acssuschemeng.5b00925

11. H. Mao, X. Chen, R. Huang, M. Chen, R. Yang, P. Lan, M. Zhou, F. Zhang, Y. Yang, X. Zhou, Fast preparation of carbon spheres from enzymatic hydrolysis lignin: Effects of hydrothermal carbonization conditions. Sci. Rep. (2018). https://doi.org/10.1038/s41598-018-27777-4

12. D. Saha, Y. Li, Z. Bi, J. Chen, J. Keum, D. Hensley, H. Grappe, H. Meyer, S. Dai, P. Paranthaman, A. Naskar, Studies on supercapacitor electrode material from activated lignin-derived mesoporous carbon. Langmuir 30(3), 900-910 (2014). https://doi.org/10.1021/la404112m

13. S. Hu, Y.L. Hsieh, Ultrafine microporous and mesoporous activated carbon fibers from alkali lignin. J. Mater. Chem. A 1, 11279-11288 (2013). https://doi. org/10.1039/C3TA12538F

14. M. Snowdon, A. Mohanty, M. Misra, A study of carbonized lignin as an alternative to carbon black. ACS Sustain. Chem. Eng. 2(5), 1257-1263 (2014). https://doi.org/10.1021/sc500086v

15. C.I. Contescu, S.P. Adhikari, N.C. Gallego, N.D. Evans, B.E. Biss, Activated Carbons Derived from High-Temperature Pyrolysis of Lignocellulosic Biomass. C (2018). https://doi.org/10.3390/c4030051

16. D. Wu, H. Xu, M. Hakkarainen, From starch to polylactide and nanographene oxide: Fully starch derived high performance composites. RSC Adv. 6, 54336-54345 (2016). https://doi.org/10.1039/C6RA08194K

17. S. Hassanzadeh, N. Aminlashgari, M. Hakkarainen, Chemo-selective high yield microwave assisted reaction turns cellulose to green chemicals. Carbohydr. Polym. 112, 448-457 (2014). https://doi.org/10.1016/j.carbpol. 2014.06.011

18. K.H. Adolfsson, S. Hassanzadeh, M. Hakkarainen, Valorization of cellulose and waste paper to graphene oxide quantum dots. RSC Adv. 5, 26550-26558 (2015). https://doi.org/10.1039/C5RA01805F

19. N.B. Erdal, K.H. Adolfsson, T. Pettersson, M. Hakkarainen, Green strategy to reduced Nanographene oxide through microwave assisted transformation of cellulose. ACS Sustain. Chem. Eng. 6, 1246-1255 (2018). https://doi.org/ 10.1021/acssuschemeng.7b03566

20. S. Kang, X. Li, J. Fan, J. Chang, Classified separation of lignin hydrothermal liquefied products. Ind Eng Chem Res 50(19), 11288-11296 (2011). https:// doi.org/10.1021/ie2011356

21. M. Si, J. Zhang, Y. He, Z. Yang, X. Yan, M. Liu, S. Zhuo, S. Wang, X. Min, C. Gao, L. Chai, Y. Shi, Synchronous and rapid preparation of lignin nanoparticles and carbon quantum dots from natural lignocellulose. Green Chem. 20, 3414-3419 (2018). https://doi.org/10.1039/C8GC00744F

22. S. Elaigwu, G. Greenway, Microwave-assisted and conventional hydrothermal carbonization of lignocellulosic waste material: Comparison of the chemical and structural properties of the hydrochars. J. Anal. Appl. Pyrolysis 118, 1-8 (2016). https://doi.org/10. 1016/j.jaap.2015.12.013

23. Y. Piao, B. Chen, Self-assembled graphene oxide-gelatin nanocomposite hydrogels: Characterization, formation mechanisms, and $\mathrm{pH}$-sensitive drug release behavior. J. Polym. Sci. B 53, 356-367 (2014). https://doi.org/10.1002/ polb.23636 
24. Y. Piao, B. Chen, One-pot synthesis and characterization of reduced graphene oxide-gelatin nanocomposite hydrogels. RSC Adv. 6(8), 61716181 (2016). https://doi.org/10.1039/C5RA20674J

25. S. Shaibu, F. Adekola, H. Adegoke, O. Ayanda, A. Comparative, Study of the adsorption of methylene blue onto synthesized nanoscale zero-valent ironbamboo and manganese-bamboo composites. Materials. 7, 4493-4507 (2014). https://doi.org/10.3390/ma7064493

26. L. Zhang, L. Tu, Y. Liang, Q. Chen, Z. Li, C. Li, Z. Wang, W. Li, Coconut-based activated carbon fibers for efficient adsorption of various organic dyes. RSC Adv. 8, 42280-42291 (2018). https://doi.org/10.1039/C8RA08990F

27. S. Nardecchia, D. Carriazo, M.L. Ferrer, M. Gutierrez, F. del Monte, Three dimensional macroporous architectures and aerogels built of carbon nanotubes and/or graphene: Synthesis and applications. Chem. Soc. Rev. 42, 794-830 (2013). https://doi.org/10.1039/C2CS35353A

28. Q. Fang, B. Chen, Self-assembly of graphene oxide aerogels by layered double hydroxides cross-linking and their application in water purification. J. Mater. Chem. A 2, $8941-8951$ (2014). https://doi.org/10.1039/C4TA00321G

29. Z. Ding, F. Li, J. Wen, X. Wang, R. Sun, Gram-scale synthesis of singlecrystalline graphene quantum dots derived from lignin biomass. Green Chem. 20, 1383-1390 (2018). https://doi.org/10.1039/C7GC03218H

30. D. Kim, K. Lee, K. Park, Upgrading the characteristics of biochar from cellulose, lignin, and xylan for solid biofuel production from biomass by hydrothermal carbonization. J Indust Eng Chem 42, 95-100 (2016). https:// doi.org/10.1016/j.jiec.2016.07.037

31. L. Bokobza, J. Bruneel, M. Couzi, Raman spectra of carbon-based materials (from graphite to carbon black) and of some silicone composites. C. 1, 77 94 (2015). https://doi.org/10.3390/c1010077

32. E. Biru, H. lovu, Graphene Nanocomposites Studied by Raman Spectroscopy (IntechOpen, 2018). https://doi.org/10.5772/intechopen.73487

33. K. Tsirka, A. Katsiki, N. Chalmpes, D. Gournis, A. Paipetis, Mapping of graphene oxide and single layer graphene flakes - Defects annealing and healing. Front Mater (2018). https://doi.org/10.3389/fmats.2018.00037

34. L. Ballesteros, J. Teixeira, S. Mussatto, Chemical, functional, and structural properties of spent coffee grounds and coffee Silverskin. Food Bioproc. Tech. 7, 3493-3503 (2014). https://doi.org/10.1007/s11947-014-1349-z

35. H. Xu, L. Xie, M. Hakkarainen, Coffee-ground-derived quantum dots for aqueous Processable Nanoporous graphene membranes. ACS Sustain. Chem. Eng. 5, 5360-5367 (2017). https://doi.org/10.1021/acssuschemeng. $7 \mathrm{~b} 00663$

36. G. Melilli, K. Adolfsson, A. Impagnatello, G. Rizza, M. Hakkarainen, Intriguing Carbon Flake Formation during Microwave-Assisted Hydrothermal Carbonization of Sodium Lignosulfonate, Global Challenges (2020), p. 1900111. https://doi.org/10.1002/gch2.201900111

37. J. Pang, W. Zhang, J. Zhang, G. Cao, M. Han, Y. Yang, Facile and sustainable synthesis of sodium lignosulfonate derived hierarchical porous carbons for supercapacitors with high volumetric energy density. Green Chem. 19 3916-3926 (2017). https://doi.org/10.1039/C7GC01434A

38. K. Shimin, X. Li, J. Fan, J. Chang, Characterization of Hydrochars produced by hydrothermal carbonization of lignin, cellulose, D-xylose, and wood meal. Ind. Eng. Chem. Res. 51, 9023-9031 (2012). https://doi.org/10.1021/ie300565d

39. M.M. Titirici, R. White, C. Falco, M. Sevilla, Black perspectives for a green future: Hydrothermal carbons for environment protection and energy storage. Energ. Environ. Sci. 5, 6796-6822 (2012). https://doi.org/10.1039/ C2EE21166A

40. K. Adolfsson, M. Golda-Cepa, N. Erdal, J. Duch, A. Kotarba, M. Hakkarainen, Importance of surface functionalities for antibacterial properties of carbon spheres. Adv Sustainable Syst 3, 1800148 (2019). https://doi.org/10.1002/ adsu. 201800148

41. W. Gindl-Altmutter, J. Köhnke, C. Unterweger, N. Gierlinger, J. Keckes, J. Zalesak, O. Rojas, Lignin-based multiwall carbon nanotubes. Composites Part A 121, 175-179 (2019). https://doi.org/10.1016/j.compositesa.2019.03.026

42. W. Sagues, A. Jain, D. Brown, S. Aggarwal, A. Suarez, M. Kollman, S. Park, D. Argyropoulos, Are lignin-derived carbon fibers graphitic enough? Green Chem. 21, 4253-4265 (2019). https://doi.org/10.1039/C9GC01806A

43. V. Luan, J. Chung, E. Kim, S. Hur, The molecular level control of threedimensional graphene oxide hydrogel structure by using various diamines. Chem. Eng. J. 246, 64-70 (2014). https://doi.org/10.1016/j.cej.2014.01.105

44. A. Bourlinos, D. Gournis, D. Petridis, T. Szabó, A. Szeri, I. Dékány, Graphite oxide: Chemical reduction to graphite and surface modification with primary aliphatic amines and amino acids. Langmuir. 19, 6050-6055 (2003). https://doi.org/10.1021/la026525h
45. O. Compton, D. Dikin, K. Putz, C. Brinson, S. Nguyen, Electrically conductive "alkylated" graphene paper via chemical reduction of amine-functionalized graphene oxide paper. Adv. Mater. 22, 892-896 (2010). https://doi.org/10. 1002/adma.200902069

46. C. Wan, M. Frydrych, B. Chen, Strong and bioactive gelatin-graphene oxide nanocomposites. Soft Matter 7, 6159-6166 (2011). https://doi.org/10.1039/ C1SM05321C

47. E.M. Zadeh, A. Yu, L. Fu, M. Dehgan, I. Sbarski, I. Harding, Physical and thermal characterization of graphene oxide modified gelatin-based thin films. Polym. Compos. 35, 2043-2049 (2014). https://doi.org/10.1002/pc.22865

48. F. Li, X. Wang, T. Yuan, R. Sun, A lignosulfonate-modified graphene hydrogel with ultrahigh adsorption capacity for $\mathrm{Pb}(\mathrm{II})$ removal. J. Mater. Chem. A 4, 11888-11896 (2016). https://doi.org/10.1039/C6TA03779H

49. Z. Feng, T. Danjo, K. Odelius, M. Hakkarainen, T. Iwata, A.-C. Albertsson, Recyclable fully biobased chitosan adsorbents spray-dried in one-pot to microscopic size and enhanced adsorption capacity. Biomacromolecules. 20, 1956-1964 (2019). https://doi.org/10.1021/acs.biomac.9b00186

50. Y. Shen, B. Chen, Sulfonated graphene Nanosheets as a superb adsorbent for various environmental pollutants in water. Environ. Sci. Technol. 49, 7364-7372 (2015). https://doi.org/10.1021/acs.est.5b01057

51. R. Xie, Y. Jin, Y. Chen, W. Jiang, The importance of surface functional groups in the adsorption of copper onto walnut shell derived activated carbon. Water Sci. Technol. 76(11), 3022-3034 (2017). https://doi.org/10.2166/wst.2017.471

52. X. Mi, G. Huang, W. Xie, W. Wang, Y. Liu, J. Gao, Preparation of graphene oxide aerogel and its adsorption for Cu2+ ions. Carbon. 50, 4856-4864 (2012). https://doi.org/10.1016/j.carbon.2012.06.013

53. C. Jiao, J. Xiong, J. Tao, S. Xu, D. Zhang, H. Lin, Y. Chen, Sodium alginate/ graphene oxide aerogel with enhanced strength-toughness and its heavy metal adsorption study. Int. J. Biol. Macromol. 83, 133-141 (2016). https:// doi.org/10.1016/j.ijbiomac.2015.11.061

54. L. Pan, Z. Wang, Q. Yang, R. Huang, Efficient removal of Lead, copper and cadmium ions from water by a porous calcium alginate/graphene oxide composite aerogel. Nanomaterials 8, 957-997 (2018). https://doi.org/10. 3390/nano8110957

55. Y. Chen, L. Chen, H. Bai, L. Li, Graphene oxide-chitosan composite hydrogels as broad-spectrum adsorbents for water purification. J. Mater. Chem. A 1, 1992-2001 (2013). https://doi.org/10.1039/C2TA00406B

56. Z. Sui, Q. Meng, X. Zhang, R. Ma, B. Cao, Green synthesis of carbon nanotube-graphene hybrid aerogels and their use as versatile agents for water purification. J. Mater. Chem. 22, 8767-8771 (2012). https://doi.org/10. 1039/C2JM00055E

57. J. Gong, J. Liu, X. Chen, Z. Jiang, X. Wen, E. Mijowska, T. Tang, Converting realworld mixed waste plastics into porous carbon nanosheets with excellent performance in the adsorption of an organic dye from wastewater. J. Mater. Chem. A 3, 341-351 (2015). https://doi.org/10.1039/C4TA05118A

58. R.R. Elmorsi, S.T. El-Wakeel, W.A. El-Dein, H.R. Lotfy, W.E. Rashwan, M. Nagah, S.A. Shaaban, S.A. Ahmed, I.Y. El-Sherif, K.S. Abou-El-Sherbini, Adsorption of methylene blue and $\mathrm{Pb} 2+$ by using acid-activated Posidonia oceanica waste. Sci. Rep. (2019). https://doi.org/10.1038/s41598-019-39945-1

59. M. Mende, D. Schwarz, C. Steinbach, R. Boldt, S. Schwarz, Simultaneous adsorption of heavy metal ions and anions from aqueous solutions on chitosan-investigated by spectrophotometry and SEM-EDX analysis. Colloids and Surfaces A: Physicochem Eng Aspects 510, 275-282 (2016). https://doi. org/10.1016/j.colsurfa.2016.08.033

60. X. Liu, L. Huang, L. Wang, C. Wang, X. Wu, G. Dong, Y. Liu, Preparation, adsorptive properties and chemical regeneration studies of high-porous activated carbon derived from Platanus orientalis leaves for $\mathrm{Cr}(\mathrm{VI})$ removal. J. Water Health 16.5, 814-826 (2018). https://doi.org/10.2166/wh.2018.068

61. X. Yi, F. Sun, Z. Han, F. Han, J. He, M. Ou, J. Gu, X. Xu, Graphene oxide encapsulated polyvinyl alcohol/sodium alginate hydrogel microspheres for cu (II) and U (VI) removal. Ecotoxicol. Environ. Saf. 158, 309-318 (2018). https://doi.org/10.1016/j.ecoenv.2018.04.039

62. Y. He, S. Li, X. Li, Y. Yang, A. Tang, L. Du, Z. Tan, D. Zhang, H. Chen, Graphene ( $\mathrm{rGO}$ ) hydrogel: A promising material for facile removal of uranium from aqueous solution. Chem. Eng. J. 338, 333-340 (2018). https:// doi.org/10.1016/j.cej.2018.01.037

\section{Publisher's Note}

Springer Nature remains neutral with regard to jurisdictional claims in published maps and institutional affiliations. 